\title{
METHOD OF ACHIEVING ACCURACY OF THERMO-MECHANICAL TREATMENT OF LOW-RIGIDITY SHAFTS
}

\author{
Antoni Świć1, Aleksandr Draczew², Arkadiusz Gola ${ }^{3}$ \\ 1 Institute of Technological Systems of Information, Lublin University of Technology, Nadbystrzycka Street 36, \\ 20-618 Lublin, Poland, e-mail: a.swic@pollub.pl \\ 2 Faculty of TM, Togliatti State University, 12 Belorusskaia Street 445021 Togliatti, Russia \\ ${ }^{3}$ Department of Enterprise Organization, Lublin University of Technology, Nadbystrzycka Street 38, 20-618 \\ Lublin, Poland, e-mail: a.gola@pollub.pl
}

Received: 2015.12.15

Accepted: 2016.02.01

Published: 2016.03.01

\begin{abstract}
The paper presents a method combining the processes of straightening and thermal treatment. Technological processes with axial strain were considered, for the case of heated material and without its heating. The essence of the process in the case of heated material consisted in the fact that if under tension all longitudinal forces in the first approximation are uniform - the same strains are generated. The presented technological approach, aimed at reducing the curvature of axial-symmetrical parts, is acceptable as the process of rough, preliminary machining, in the case of shafts with the ratio $\mathrm{L} / \mathrm{D} \leq 100$ ( $L$ - shaft length, $d$ - shaft diameter) and without a tendency of strengthening. To improve the accuracy and stability of geometric form of low-rigidity parts, a method was developed that combines the processes of straightening and heat treatment. The method consists in that axial strain - tension, is applied to the shaft during heating, and during cooling the product is fixed in a fixture, the cooling rate of the shaft being several-fold greater than that of the fixture. A device is presented for the realisation of the method of controlling the process of plastic deformation of lowrigidity shafts. In the case of the presented device and the adopted calculation scheme, a method was developed that permits the determination of the length of shaft section and of the time of its cooling.
\end{abstract}

Keywords: low-rigidity shafts, thermo-mechanical treatment, accuracy.

\section{INTRODUCTION}

Parts with low rigidity often undergo warping due to residual stress appearing under loading of a semi-finished products due to plastic strains of various values. In the course of rolling of long semi-finished products one can identify two causes for the appearance and development of residual stress, i.e. non-uniformity of plastic deformations of metal during its cold-working and non-uniformity of temperature field during cooling $[8,9]$.

To reduce the level of residual stress in lowrigidity parts, depending on their physico-mechanical properties, we can apply annealing or tempering $[2,4,5,14]$. One of the methods of ensuring the maintenance of shape is heat treatment at rigid fixing of the positioning of the semifinished product. In the course of heat treatment, without such stabilisation (e.g. during tempering) there is practically always a change in shaft dimensions (relaxation takes place with creep). The complex mechanical condition of material during heat treatment of products in a tensile condition, combined with the diversity of phase conditions, can cause a change of the dimensions of the products in the course of successive machining operations or during storage. Warping in free state takes place also after heat treatment, initially often in a specific direction (bending, tension), be- 
fore the termination of phase transformations and non-elastic deformations. The stabilisation of a product during quenching is also characterised by specific features. For example, when the stabilisation of a quenched product lasts relatively long, deformations are slight (in the case of test pieces $1-2 \%$ of the value of plastic deformation generated under load). Tempering realised after quenching, in particular with the occurrence of residual austenite, when phase transformations take place in the material, causes an increase of secondary strains that add up (along the same directions) with strains generated previously.

To minimise warping - deformations of lowrigidity shafts in the course of heat treatment under load, we need to create the conditions for the appearance of suitable plastic deformation or phase transformation $[7,10]$. For example, during the martensite transformation steel loses strength and undergoes a slight deformation. At quenching temperatures the field of residual stresses gets reduced to zero and is uniform in the section - the layer hardened by cold-working gets fully eliminated. It is technologically difficult to preserve such a condition of the material during cooling to ambient temperature, as during cooling with the load removed the condition of conformance of plastic-elastic deformations is not met. In this case it is to the point to analyse the specific technological aspect of product preparation for heat treatment. It s necessary that the geometric parameters of the semi-finished product after straightening and machining do not exceed the tolerance for profiling. Non-uniformity of deformations in the section and along the semi-finished product is determined by inaccuracy of fabrication (especially the value of eccentric of the semifinished product - non-coincidence of the technological and theoretical axes). Under loading, the lack of symmetry in the cross-section causes the generation of a bending moment, with resultant deformations $[6,11,13]$.

\section{CHARACTERISATION OF THE METHOD OF THERMO-MECHANICAL TREATMENT OF LOW-RIGIDITY SHAFTS}

To increase the accuracy and stability of form of low-rigidity shafts a technique was developed that combines the processes of straightening and heat treatment. Successive technological operations (processes) were considered, with the application of axial deformation, both for the case of heated material and without its heating. Each of the operations can be an autonomous one, depending on the function of the product. The essence of the first technological process consists in that, during tension, all longitudinal forces are equivalent, in the first approximation, i.e. the same stresses are generated (Figure 1a). The value of the working stresses $\mathrm{s}_{r}$ can be determined from the stress diagram with relation to the relative deformation $\mathrm{e}_{r}$ (Figure 1c).

On section that are bent in spite of the tension applied, straightening of the semi-finished product also takes place, due to which the relative deformations of longitudinal layers of those sections are different. Usually the radius of the curvature is not less than 20-30-fold height of crosssection of rolled semi-finished products, and the character of distribution of deformations in the cross-section of shaft during straightening can be adopted like that in the bending of a straight-line beam. In this case the distribution of relative deformations along the height of the semi-finished product conforms with a linear relation (Fig. 1b), and their highest and lowest values in the extreme outer and inner layers of the shaft can be represented as:

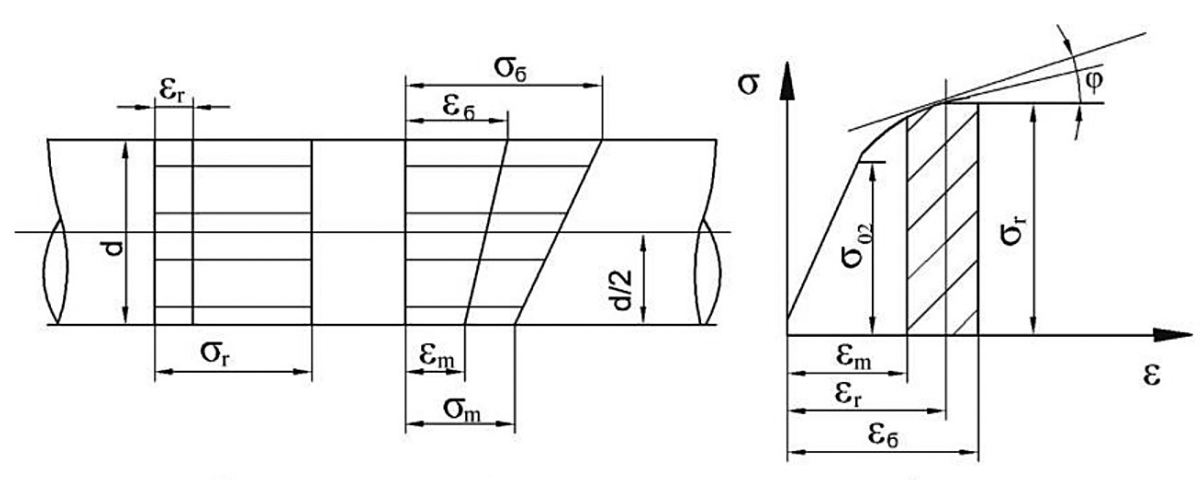

a)

b)

c)

Fig. 1. Deformations and stresses during axial loading 


$$
\varepsilon_{\sigma}=\varepsilon_{r}+\frac{d}{2 r_{k}}, \quad \varepsilon_{m}=\varepsilon_{r}-\frac{d}{2 r_{k}},
$$

where: $\varepsilon_{\sigma}$ - highest value of deformation,

$\varepsilon_{r}$ - relative deformation,

$r_{k}-$ radius of curvature of semi-finished product,

$\varepsilon_{m}-$ lowest value of deformation.

The values of relative elongations fall within the range represented in the stress diagram by the zone $\varepsilon_{\sigma}-\varepsilon_{m}$ (Figure 1c). It can be assumed that the tangent modulus of longitudinal elasticity $E_{\mathrm{y}}$ is constant. In this case, the distribution of stresses along the height of the shaft also conforms to a linear relationship (Figure 1b). Stresses within the zone of relative deformations can be written as:

$$
\sigma_{\sigma}=\sigma_{r}+\frac{E_{y}}{E} v, \quad \sigma_{m}=\sigma_{r}-\frac{E_{y}}{E} v,
$$

where: $\sigma_{\sigma}$ - highest value of stress,

$\sigma_{r}$ - working stress,

$E_{\mathrm{y}}$ - tangent modulus of longitudinal elasticity,

$E$ - Young modulus,

$v-$ stress coordinate with relation to the central layer of semi-finished product.

The tensile force and the bending moment can be determined from the relation:

$$
F_{r o z}=\sigma_{r} \cdot S_{w}, \quad M_{z g}=\frac{E_{y} \cdot v}{E \cdot J},
$$

where: $F_{r o z}-$ tensile force,

$S_{w}^{r o z}$ - cross-section area of shaft,

$M_{z g}^{w}$ - bending moment,

$J-$ moment of inertia.

As a result of non-uniform distribution of stresses relative to the diameter on the bent sections, there is an effect of external forces that should be balanced by an external bending moment. That moment is generated through a shift of the centre of gravity of the cross-section of the shaft section relative to the line along the tensile force acts. In this case the bending moment from the external forces is equal to $M_{\text {zewn }}=F_{\text {roz }} \times y_{\mathrm{e}}$, where $y_{e}-$ absolute value of the part of final bending that can be represented by means of known values as follows:

$$
y_{e}=\frac{J \cdot E_{y}}{r_{k} \cdot S_{w} \cdot \sigma_{r}} .
$$

The value $y_{e}$ is only a part of the final bend remaining after the straightening. The basic part of the final bend is generated at the removal of the external tensile load, as a result of relaxation of residual stresses and non-elastic effects, i.e. shaft sections bent earlier partially recreate their curvature as apart from the tensile force also the bending moment originating from those forces is removed as well.

Based on the analytical study of the processes of axial deformation of shafts one can formulate the conclusion that the final curvature of a product depends on the initial warp $1 / r_{k}$, on the physicomechanical properties of the material and on the technology of fabrication. Therefore, one should take note of several approaches to the design of technological processes of machining of low-rigidity shafts, with relation to the material of the semi-finished product. When the material of the semi-finished product has a growing characteristic, during the determination of the external tensile load the zone of relative elongations $\varepsilon_{\sigma}-\varepsilon_{m}$ should correspond to the diagram section $\sigma-\varepsilon$, with minimum tangent modulus of longitudinal elasticity. In the case of low-carbon steels, this is the zone of plasticity $\left(E_{\mathrm{y}}=0\right)$. When determining the axial deformation of materials with a tendency to strengthening, zone $\varepsilon_{\sigma}-\varepsilon_{m}$ in diagram $\sigma-\varepsilon$ should be situated after the initial section with a steep slope of the stress curve. Low-carbon and high-alloy steels are characterised by a steep rise of stresses on the section of uniform elongation, as a result of high values of the tangent modulus of longitudinal elasticity. Large axial loads are required, which causes that the deformation notable exceed the strength limit of the material.

The presented technological approach to an improvement of the curvature of axial-symmetrical parts can be accepted as a process of roughing, preliminary machining, in the case of shafts with the ratio $L / d \leq 100$ and without a tendency of strengthening.

To increase the accuracy and stability of geometric form of low-rigidity parts a method was developed that combines the processes of straightening and heat treatment $[1,3,12]$. The method consists in that axial strain - tension, is applied to the shaft during heating (quenching temperature), and during cooling the product is fixed in a fixture, the cooling rate of the shaft being severalfold greater than that of the fixture (Figure 2a). In Figures 2 and 3 the numeric character 1 is used to denote the fixture, and 2 - the product and the characteristics during heating and cooling.

In the theoretical calculations it was assumed that the curvature of the axis of the semi-finished product $y$ is described by the sinusoid: 


$$
y=\frac{\alpha \cdot \sin \pi \cdot x}{L},
$$

and the value of change in the length of the semifinished product was determined from the relation (Figure 2a):

$$
\Delta L=\frac{\pi^{2} \cdot y_{\alpha}^{2}}{4 L}
$$

where: $\alpha$ - initial deflection,

$$
y_{\alpha} \text { - initial curvature. }
$$

In the tension of a semi-finished product with initial curvature not exceeding $1 \%$ on length $L$, the value of deformations $y_{\alpha 1}$ is related with the initial curvature $y_{\alpha}$ by the following relation:

$$
y_{\alpha 1}=\frac{y_{\alpha}}{1+\frac{F_{r o z}}{F_{k r}}},
$$

from which we can determine the value of axial load required to reduce the deflection:

$$
F_{r o z}=F_{k r} \cdot \frac{y_{\alpha}}{y_{\alpha 1}-1},
$$

where: $F_{k r}$ - critical axial force.

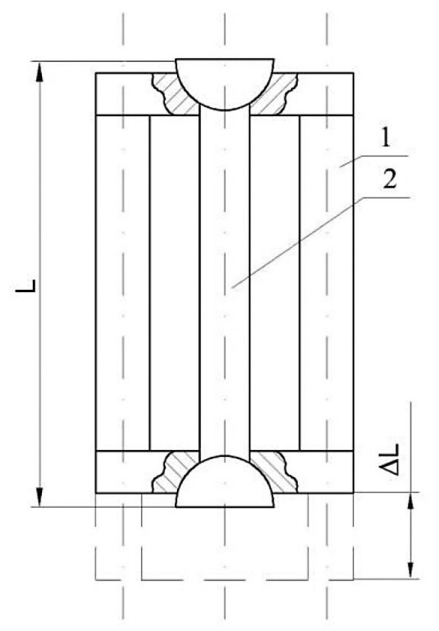

a)

Fig. 2. Simplified schematic of technological realisation of the method of machining $-a$ ), characteristics during heating and cooling $-b$ )

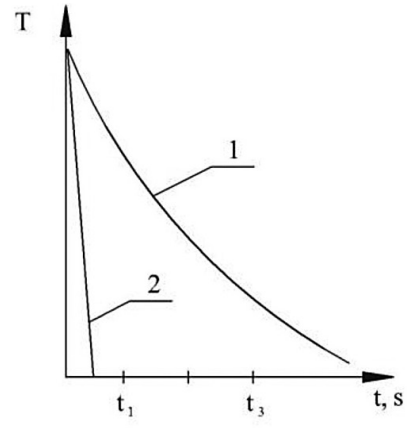

a)

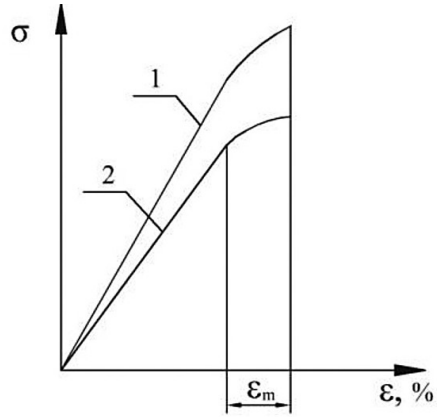

b)

Fig. 3. Relations of cooling temperature of fixture and semi-finished product - a), relation of stresses and relative elongations $-b$ ) 
thermal expansion coefficients of the product $\left(\alpha_{w}\right)$ and the fixture $\left(\alpha_{u r z}\right)$, as well as of their lengths (the semi-finished product is positioned in the fixture and mounted by its ends on the fronts - Figure 2a). The difference between the elongations of the semi-finished product and the fixture is determined from the relation:

$$
\Delta L=\alpha_{u r z}\left(T^{\circ}\right) \cdot T^{\circ} \cdot L_{u r z}-\alpha_{w}\left(T^{\circ}\right) \cdot T^{\circ} \cdot L_{w} .
$$

where: $\Delta L$ - difference of elongations of semifinished product and fixture,

$\alpha_{u r z}-$ thermal expansion coefficient of fixture,

$\alpha_{w}-$ thermal expansion coefficient of product,

$T^{o}$ - temperature,

$L_{u r z}$ - length of fixture,

$L_{w}-$ length of product.

Analysis of the relation shows that with increase in the heating temperature the difference of elongations increases in a non-linear manner. To stabilise the geometry of the product, during heat treatment in a fixture the produced summary elongation should be not less than $1 \%$ of the product length.

During heating the semi-finished product undergoes elongation by:

$$
\Delta L=\left(\Delta_{1}+\Delta_{2}+\Delta_{02}+\Delta_{3}\right) \cdot L \cdot K_{1}
$$

where: respective elongations caused by: $\Delta_{1}-$ initial curvature of the element, $\Delta_{2}$ - difference of thermal expansion coefficients of the materials, $\Delta_{02}$ - conventional range of proportionality at $T^{\circ}=20^{\circ} \mathrm{C}, \Delta_{3}$ - relative elongation of the product,

$K_{1}=S_{\mathrm{w}} / S_{\mathrm{prz}}-$ coefficient accounting for fixture compression $\left(S_{\mathrm{prz}}\right.$ - area of crosssection of the fixture).

In the proposed solution, during heating the shaft deforms at an assumed rate, in accordance with the heat treatment technology. The fixture expands to a greater extent than the product, proportionally to the difference in the coefficients of linear expansion, and the rate of cooling is from 1.5 to 3 -fold lower than shaft cooling rate.

This permits stabilisation of axial load at the beginning of cooling and gradual removal of the load. In the calculation of typical processes it is necessary to solve the problem of non-stationary thermal conductivity, i.e. to define the relation between temperature change and the amount of heat transmitted in time, for any point of a body. In the case of solids, the differential equation of thermal conductivity has the form:

$$
\frac{\partial T}{\partial t}=b\left(\frac{\partial^{2} T}{\partial x^{2}}+\frac{\partial^{2} T}{\partial y^{2}}+\frac{\partial^{2} T}{\partial z^{2}}\right) .
$$

For analytical solution of equation (12) we need to define the boundary conditions: 1 ) initial temperature distribution in the material; 2) effect of the environment on the surface of the material, which can be defined in three ways, by means of: a) surface temperature, b) amount of heat penetrating the surface, c) ambient temperature and heat transfer coefficient g. According to the Newton Law:

$$
d Q=\lambda\left(T_{p r z}^{o}-T_{c}^{o}\right) d S
$$

where: $d Q$ - amount of heat,

$T_{p r z}^{o}, T_{c}^{\circ}$ - temperature of apparatus wall and liquid,

$d S$ - unit of surface area,

$b$ - coefficient of temperature conductivity.

The result of solving equation (12) is a function that should simultaneously meet the boundary conditions. The function we seek depends on a large number of parameters which can be groupped into two dimensionless complexes:

- the Biot criterion $-B_{i}=\frac{\gamma \cdot \delta_{p r z}}{\varphi}$,

- the Fourier criterion $-F_{0}=\frac{b \cdot t}{\delta_{p r z}}$,

where: $\gamma$ - coefficient of heat transfer on the boundary surface,

$\delta_{p r z}-$ wall thickness of the apparatus,

$\varphi$ - coefficient of heat conductivity,

$t$ - cooling time.

Based on the second theorem of similarity, the function sought, in the form of dimensionless temperature $Q / Q^{\prime}$, in various points can be presented as:

$$
\frac{Q}{Q^{\prime}}=\Phi\left(\mathrm{B}_{i}, F_{0}, \Delta L\right),
$$
where: $\Delta L=\frac{x}{\delta_{p r z}} L, x-$ coordinates of the heating
zone.

A shaft can be represented as an infinitely long cylinder with radius $R$; in this case the differential equation of thermal conductivity will have the form:

$$
\frac{\partial Q}{\partial t}=b\left(\frac{\partial^{2} Q}{\partial t^{2}}+\frac{\partial Q}{t \partial t}\right) .
$$

Boundary conditions: at $r=R ; \frac{\partial Q}{\partial t}=\gamma \frac{Q}{\varphi_{c}}$.

Initial conditions: at $t=0 ; Q=Q^{\prime}$. 
The graph of the relation $\varepsilon=\psi\left(T^{\circ}\right)$ (Figure $2 \mathrm{~b}$ ) shows the character of the relation between the deformation of the fixture and the shaft during cooling, where $\varepsilon_{\text {ost }}$ - semi-finished product deformation by the value of $\varepsilon_{m}$ (Figure $3 b$ ) - in the case of difference between the thermal expansion coefficients.

If the thermal expansion coefficients of the shaft and the fixture are identical, the axial deformation can be obtained (in accordance with the calculations) as the difference between the length of the fixture and the shaft, or through proper selection of the rate of their cooling (Figure 3a).

Axial tensile stresses in heat treatment are determined from the relation:

$$
\sigma_{r}=\alpha_{T} \cdot \Delta T^{\circ} \cdot E \cdot \frac{S_{w}}{S_{p r z}},
$$

where: $\Delta T$ - temperature difference between the shaft and the fixture during cooling, $\alpha_{T}=\alpha(T)+T \frac{d \alpha}{d T}-$ true difference of thermal expansion coefficients.

During quenching of a stepped semi-finished product (shaft) the conditions of equality of working stresses at each step of the shaft are determined from the relation:

$$
S_{w} \cdot E_{w}^{n} \cdot \alpha\left(T^{\circ}\right) \cdot \frac{T^{\circ}}{S_{p r z}^{n}}=S_{w}^{n-1} \cdot E_{w}^{n-1} \cdot \frac{\alpha\left(T^{\circ}\right)}{F_{p r z}^{n-1}},
$$

where: $S_{w}^{n}, S_{w}^{n-1}, S_{p r z}^{n}, S_{p r z}^{n-1}-$ planes of crosssections of shaft and fixture at steps " $n$ " and " $n-1$ ".

At the first stage of cooling of a shaft (semifinished product) in a fixture, i.e. when the difference of their temperatures is the greatest, the value of small final deformations of the shaft is the sum of elastic deformations $\mathrm{e}_{\mathrm{y}}$, plastic deformations $\mathrm{e}_{\mathrm{pl}}$ and temperature deformation $\mathrm{e}_{\mathrm{T}}$ :

$\varepsilon_{\Sigma}=\varepsilon_{y}+\varepsilon_{p l}+\varepsilon_{T}$,
where: $\varepsilon_{T}=\int_{T_{0}}^{T_{1}} \alpha_{T}\left(T^{\circ}\right) d T$.

In the developed technology of heat treatment involving the application of axial deformations, stresses remaining from preceding operations are eliminated $[6,12]$, irrespective of the properties of the material. However, during cooling of a shaft under tension, mounted in a fixture, new tensile stresses are generated, distributed uniformly in the cross-section of the semi-finished product. The level of the final stresses is determined by the relation:

$$
\sigma=E \cdot\left(\varepsilon_{y}+\varepsilon_{p l}+\varepsilon_{T}\right) .
$$

During cooling, the semi-finished product cools down faster on the outside than on the inside, and the stresses in the surface layers will be of an opposite sign to those inside the semifinished product. At the point of complete cooling, the signs of the stresses will be reversed. The primary advantage of the proposed technological undertaking consists in that the stresses in the outer layers will be of the same sign, which precludes the warping of the part.

Further machining, with uniform removal of material relative to the shaft axis, will also not cause any warping.

The relations presented are correct with the assumption if linearity of the model. Non-linearity, i.e. plastic deformation during quenching with axial deformation, does not exceed $1 \%$, which permits approximation of the relation with an accuracy that is sufficient in practice.

The process of quenching is the beginning of the technology of heat treatment, and therefore the processes of relaxation and other consequences are not considered here.

Active control of the condition of materials in the process of heating and deformation of the semi-finished product permits the control of residual stresses during the whole process of fabrication.

\section{SYSTEM FOR THE CONTROL OF THE PROCESS OF PLASTIC DEFORMATION OF LOW-RIGIDITY SHAFTS}

The process of achieving suitable accuracy of shafts through their thermal-mechanical treatment takes place in a system whose schematic is presented in Figure 4. The system for the realisation of the method of control of the process of plastic deformation of low-rigidity shafts is composed of a shaft furnace 1 with sectional electric heating elements 2 . The semi-finished product to be treated is aligned in a vee block and placed in the furnace. Initially, on the semi-finished product fins are positioned, dividing the space of the shaft furnace into chambers, each of the chambers having an inlet and outlet for cooling air.

After the semi-finished product is fixed in position, the heating elements are switched on. The current value of temperature is determined by means of thermocouples situated in every chamber. When the semi-finished product temperature $T^{\circ}=300^{\circ} \mathrm{C}$ 


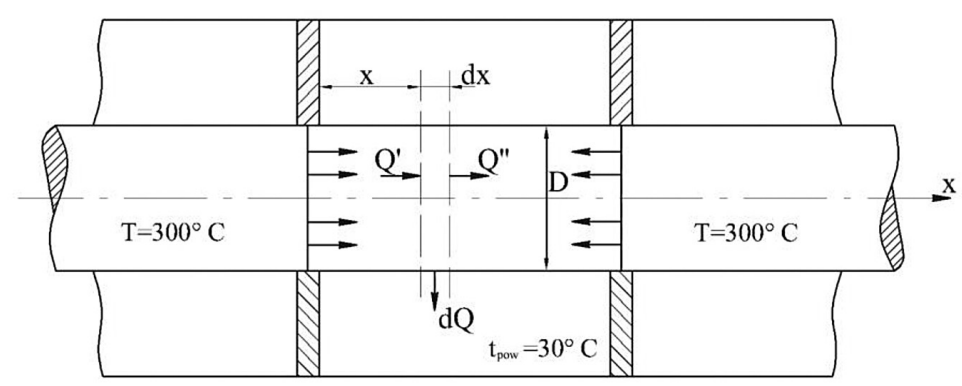

Fig. 4. Schematic of system for the control of the process of plastic deformation of low-rigidity shafts

is attained, the system of axial tension application to the semi-finished product is activated.

The physico-mechanical properties of the semi-finished product in the longitudinal direction are not uniform, therefore the time of attainment of the limit of plasticity on various sections of the shaft may be different. Registration of the point of disturbance of proportionality of axial elongation is effected by means of a pneumatic gauge (not shown in Figure 4).

The electric heating elements on the shaft section on which a zone of plastic strengthening occurs are switched off, and a compressor supplying cooling air is activated.

The air-cooled section of the semi-finished product attains temperature of $T^{\circ}=200^{\circ} \mathrm{C}$, following which heating is resumed after stopping the supply of cooling air.

\section{DETERMINATION OF LENGTH AND COOLING TIME OF SHAFT SECTION}

To achieve the correct run of the process of thermo-mechanical treatment of a shaft it is necessary to determine the length of the shaft section and the time of its cooling. The calculation scheme for the determination of those values is presented in Figure 5.
The adopted material of the semi-finished product was steel X10CrNi18-8, in the case of which: mass density $-\gamma=7900 \mathrm{~kg} / \mathrm{m}^{3}$, coefficient of thermal conductivity $-\lambda_{\mathrm{s}}=14.5 \mathrm{~W} / \mathrm{m} \cdot{ }^{\circ} \mathrm{C}$, thermal capacity $-C=0.5 \mathrm{~kJ} / \mathrm{kg} \cdot{ }^{\circ} \mathrm{C}$, coefficient of heat trans-

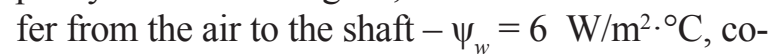
efficient of thermal conductivity $-\mu=5 \times 10^{-6} \mathrm{~m}^{2} / \mathrm{s}$.

Analysis was performed of heat transfer through a cylindrical rod whose cross-section area equals $S=\mathrm{p} \times R^{2}$, and circumference is $U=2 \pi \times R$, ( $R$ - radius of the shaft). The temperature of the rod depends functionally only on its length, that is:

$$
T^{\circ}=f(x) \text {. }
$$

The principle of temperature change on the rod length was determined, as well as the amount of heat transferred through the rod in the stationary mode. At distance $x$ from the beginning of the rod section (Figure 5) element $\mathrm{d} x$ was isolated, for which the heat balance equation was written:

$$
Q^{\prime}-Q^{\prime \prime}=d Q \text {. }
$$

According to the Fourier theorem:

$$
\begin{gathered}
Q^{\prime}=-\lambda_{p r z} \cdot S \frac{d T^{\circ}}{d x}, \\
Q^{\prime \prime}=-\lambda_{p r z} \cdot S\left(\theta+\frac{d T^{\circ}}{d x} \cdot d x\right),
\end{gathered}
$$

therefore:

$$
Q^{\prime}-Q^{\prime \prime}=d Q=\lambda_{p r z} \cdot S \frac{d^{2} T^{\circ}}{d x^{2}} \cdot d x
$$

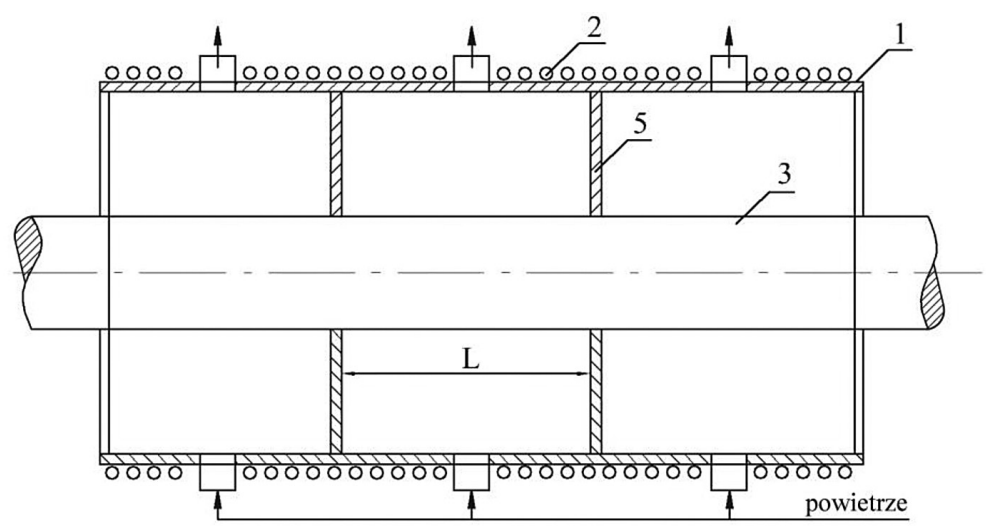

Fig. 5. Calculation scheme for the determination of shaft section length and time of its cooling 
And on the other hand:

$$
d Q=\alpha_{w} \cdot U \cdot \theta \cdot d x \text {. }
$$

Comparing (19) and (20) we obtain:

$$
\frac{d^{2} T}{d x^{2}}=\frac{\psi_{w} \cdot U \cdot T}{\lambda_{p r z} \cdot S}=m^{2} \cdot \theta,
$$

where: $m=\sqrt{\psi_{w} \cdot \frac{U}{\lambda_{p r z} \cdot S}}\left[\frac{1}{m}\right]$

The solution of equation (21) can be written in the form:

$$
T^{\circ}=C_{1} \cdot e^{m x}+C_{2} \cdot e^{-m x} .
$$

The values of coefficients $C_{1}$ and $C_{2}$ are determined from the boundary conditions.

In the case of a rod with infinite length and circular cross-section:

$$
\begin{gathered}
\frac{U}{S}=\frac{4}{D}, \\
C_{1}=x \cdot m=x \sqrt{\frac{\psi_{B} \cdot U}{\lambda_{p r z} \cdot S}}=x \sqrt{\frac{6 \cdot 4}{0,045 \cdot 14,5}}=6 x, \\
T^{\circ}=T_{0}^{\circ} \cdot e^{-m x},
\end{gathered}
$$

where: $x$ - current coordinate,

$T^{\circ}=T^{\circ}-T_{p o w}-$ excessive ambient temperature,

$T_{0}^{\circ}=T_{0}^{\circ}-T_{\text {pow }}-$ excessive initial temperature,

$T^{\circ}$ - current temperature, $T_{0}^{\circ}=300{ }^{\circ} \mathrm{C}$, $T_{\text {pow }}=30^{\circ} \mathrm{C}$.

The equation of the temperature curve for the conditions given is the following:

$$
T^{\circ}=270 \cdot e^{-6 x} \text {. }
$$

Equation (22) is used to determine the length of section $x$, on which the temperature $T^{\circ}=200{ }^{\circ} \mathrm{C}$ will be stabilised:

$$
T^{\circ}=T^{\circ}-T_{\text {pow }}=200-30=170{ }^{\circ} \mathrm{C},
$$

$\frac{170}{270}=\frac{1}{6 x} ; e^{6 x}=\frac{270}{170}=1,58 ; 6 x=0,45 ; x=0,076 \mathrm{~m}=76 \mathrm{~mm}$.

The calculation scheme for the determination of rod section cooling time is shown in Figure 6.

Amount of heat transferred through the crosssection:

$Q=\lambda_{p r z} \cdot S \cdot m \cdot T_{0}=14,5 \cdot \frac{3,14 \cdot 0,045^{2}}{4} \cdot 6 \cdot 270=37,3 \mathrm{~J}$.

Shaft section cooling time.

Criterion:

$$
\begin{gathered}
B_{i}=\psi_{w} \cdot \frac{R}{\lambda_{p r z}}=\frac{6 \cdot 0,0225}{14,5}=0,0093, \\
F_{0}=\mu \cdot \frac{\tau}{\delta_{p r z}^{2}}=5 \cdot 10^{-6} \frac{\tau}{0,0225^{2}}=0,0098 \tau .
\end{gathered}
$$

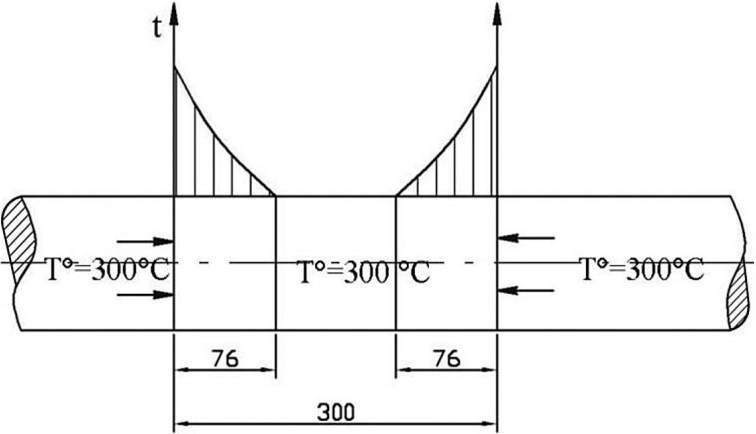

Fig. 6. Calculation scheme for the determination of rod section cooling time

Using the relation for the case of small values of $B_{\mathrm{i}}$ we obtain:

$$
T=T^{\prime} \cdot e^{-2 B_{i} \cdot F_{0}},
$$

where: $T^{\circ}=200-30=170{ }^{\circ} \mathrm{C}$,

$$
T^{\prime}=300-30=270^{\circ} \mathrm{C} \text {. }
$$

Relation (23) is used to determine the shaft section cooling time:

$$
\begin{aligned}
t=\frac{1}{2} \cdot \frac{\delta_{p r z}^{2} \cdot \ln \frac{\theta^{\prime}}{\theta}}{5 \cdot 10^{-6} \cdot 0,0093}=\frac{1}{2} \cdot \frac{0,0225^{2} \cdot \ln \frac{270}{170}}{5 \cdot 10^{-6} \cdot 0,0093}= \\
=0.025 \mathrm{~h}=90 \mathrm{~s}
\end{aligned}
$$

The amount of heat removed by air during the complete cooling of shaft section with length $L=300 \mathrm{~mm}$ at $T^{\prime}=100{ }^{\circ} \mathrm{C}$ is determined as:

$$
\begin{gathered}
Q^{\prime}=c \cdot \gamma \cdot V \cdot T^{\prime}, \\
V=\frac{\pi \cdot R^{2}}{4} \cdot L=\frac{3,14 \cdot 0,045^{2}}{4} \cdot 0,3=4,75 \cdot 10^{-4} \mathrm{~m}^{2}, \\
Q^{\prime}=0,5 \cdot 10^{3} \cdot 7900 \cdot 100 \cdot 4,75 \cdot 10^{-4}=187625 \mathrm{~J} .
\end{gathered}
$$

The amount of heat transferred through the shaft cross-section from the hot side during time $t=90 \mathrm{~s}$ is determined from the relation:

$$
Q_{\text {prz. }}=2 \cdot 37,3 \cdot 90=6714 \mathrm{~J} \text {. }
$$

In the case of the system presented here and the adopted calculation scheme the method developed permits the determination of the length of shaft section and the time of its cooling, necessary for the achievement of the required accuracy of the shaft, obtained as a result of aplication of the presented method of thermal-mechanical treatment.

\section{CONCLUSIONS}

The paper presents a method combining the processes of straightening and thermal treatment, permitting an improvement of the accuracy and sta- 
bility of the geometric form of low-rigidity shafts. The essence of the method consists in that axial strain - tension, is applied to the shaft during heating, and during cooling the product is stabilised relative to a fixture, the cooling rate of the shaft being several-fold greater than that of the fixture. A theoretical substantiation of the method is presented.

A system was developed for the thermal-mechanical treatment, permitting the achievement of required accuracy of shafts. During heating, a shaft deforms at an assumed rate, in accordance with the technology of heat treatment. The system expands to a greater extent than the product, proportionally to the difference between the coefficients of linear expansion of the materials applied, and the rate of its cooling is from 1.5 to 3 -fold lower from the cooling rate of the shaft. This permits stabilisation of axial load at the beginning of cooling, and smooth removal of the load.

For the proposed method of thermal-mechanical treatment relations were developed for the determination of the shaft section length and the time of its coling, permitting the achievement of required accuracy of the shaft in the realisation of the technological process in the proposed system.

\section{REFERENCES}

1. Draczew O., Świć A., Taranenko W., Taranenko G.: Modelowanie układu dynamicznego obróbki cieplno-mechanicznej wałów o małej sztywności. Postępy Nauki i Techniki, 5, 2010, 71-84.

2. Draczew O., Świć A., Taranenko W., Taranenko G.: Podstawy teoretyczne i doświadczalne modelowania operacji obróbki cieplno-mechanicznej wałów o małej sztywności. Postępy Nauki i Technik, 5, 2010, 55-70.

3. Halas W., Taranenko V., Świć A., Taranenko G.: Investigation of influence of grinding regimes on surface tension state. In: N.T. Nguyen et al. (Ed.) IEA/AIE 2008, LNAI 5027, Springer - Verlag Berlin Heidelberg, 2008, 749-756.
4. Li H., Shin Y.C.: Integration of thermo-dynamic spindle and machining simulation models for a digital machining system. The International Journal of Advanced Manufacturing Technology, 40(78), 648-661.

5. Lin C.W., Tu J. F., Kamman J. An integrated thermo-mechanical-dynamic model to characterize motorized machine tool spindles during very high speed rotation. International Journal of Machine Tools and Manufacture, 43(10), 2003, 1035-1050.

6. Świć A, Taranenko W, Szabelski J.: Modelling dynamic systems of low-rigid shaft grinding. Eksploatacja i Niezawodność - Maintenance and Reliability 2(50), 2011, 13-24.

7. Świć A., Gola A., Wołos D.: A method for increasing the economic effectiveness of the low rigidity shafts, Actual Problems of Economics, 11(161), 2014, 469-477.

8. Świć A., Gola A.: Economic analysis of casing parts production in a flexible manufacturing system, Actual Problems of Economics, 3(141), 2013, 526-533.

9. Świć A., Taranenko W., Gola A.: Analysis of the process of turning of low-rigidity shafts, Applied Mechanics and Materials, 791, 2015, 238-245.

10. Świć A., Wołos D., Zubrzycki J., Opielak M., Gola A., Taranenko V.: Accuracy control in the machining of low rigidity shafts, Applied Mechanics and Materials, 613, 2014, 357-367.

11. Świć A.: Technologia obróbki wałów o małej sztywności. Lublin: Wydawnictwo Politechniki Lubelskiej 2009.

12. Taranenko G, Taranenko W, Świć A, Szabelski J.: Modelling of dynamic systems of low-rigidity shaft machining. Eksploatacja i Niezawodnosc Maintenance and Reliability 4(48), 2010, 4-15.

13. Taranenko G., Taranenko V., Szabelski J., Świć A.: Systemic analysis of models of dynamic systems of shaft machining in elastic-deformable condition. Applied Computer Science, 3(2), 2007, 115-138.

14. Taranenko W., Świć A.: Urządzenia sterujące dokładnością obróbki części maszyn o małej sztywności. Wydawnictwo Politechniki Lubelskiej, Lublin 2006. 